carcinoma: comprehensive analysis of 104 cases from multicenter European database. Urology. 2005; 65: 681-6.

3. Dall'oglio MF, Antunes AA, Pompeo AC, Mosconi A, Leite KR, Srougi M: Prognostic relevance of the histological subtype of renal cell carcinoma. Int Braz J Urol. 2008; 34: 3-8.

4. Delahunt B, Bethwaite PB, Nacey JN: Outcome prediction for renal cell carcinoma: evaluation of prognostic factors for tumours divided according to histological subtype. Pathology. 2007; 39: 459-65.

5. Delahunt B, Sika-Paotonu D, Bethwaite PB, McCredie MR, Martignoni G, Eble JN, et al.: Fuhrman grading is not appropriate for chromophobe renal cell carcinoma. Am J Surg Pathol. 2007; 31: 957-60.

6. Kim H, Cho NH, Kim DS, Kwon YM, Kim EK, Rha $\mathrm{SH}$, et al.: Renal cell carcinoma in South Korea: a multicenter study. Hum Pathol. 2004; 35: 1556-63.

7. Moch H, Gasser T, Amin MB, Torhorst J, Sauter G, Mihatsch MJ: Prognostic utility of the recently recommended histologic classification and revised TNM staging system of renal cell carcinoma: a Swiss experience with 588 tumors. Cancer. 2000; 89: 604-14.

8. Patard JJ, Leray E, Rioux-Leclercq N, Cindolo L, Ficarra V, Zisman A, et al. Prognostic value of histologic subtypes in renal cell carcinoma: a multicenter experience. J Clin Oncol. 2005; 23: 2763-71.

Dr. Fabio Tavora

The Johns Hopkins Hospital

Baltimore, Maryland, USA

E-mail:ftavora@gmail.com

\title{
Re: Laparoscopic Radical Prostatectomy: Omitting a Pelvic Drain
}

\author{
David Canes, Michael S. Cohen, Ingolf A. Tuerk \\ Lahey Clinic Medical Center, Burlington, Massachusetts, USA
}

Int Braz J Urol, 34: 151-158, 2008

To the Editor,

The placement of a drain post prostatectomy is the subject of much discussion these days. A lot has been made of surgeons moving to the non-drained model of prostatectomy, the goal has been to become less invasive and reduce patient morbidity. In open prostatectomy, the drain is placed via a separate stab incision while in laparoscopic or robotic cases the drain is brought out through a pre-existing port site. In both cases, the drain is usually removed at day one in a simple manner without any additional anesthesia. The purpose of a pelvic drain is to remove the abdominal fluid contents resulting from the surgery.
This can be blood, lymph or urine. The point is what is the downside?

The drain provides an additional source of diagnostic information during the postoperative period and can help early diagnosis of postoperative problems. This is especially important in modern day surgery with patients going home in under 24 hours. Identifying potential bleeding or urinary extravagation can prevent readmissions and potentially more catastrophic complications. While some are proud of not having to use a drain post surgery, I am sure all would agree that they have at times had to place one 
post surgery or have had postoperative bleeding or urinomas that have remained undrained.

Though there are a few studies, which have addressed the avoidance for, drain in open radical prostatectomy $(1,2)$ there is only one paper that addressed the avoidance of drain following laparoscopic prostatectomy (3). This paper is a retrospective study concluding that drains may be placed selectively following laparoscopic radical prostatectomy. The authors subjectively omitted drain placement in $75 \%$ of 208 patients undergoing this operation with no ill effects. The surgeon chose to place drains based mainly on large bladder neck reconstructions or intraoperative anastomotic leak on saline bladder lavage. A randomized prospectively designed study with cystograms performed at a set time interval from surgery would give better evidence for this ongoing debate. A crucial endpoint for investigation would be the objective benefits of omitting drain placement such as validated assessment of postoperative patient discomfort.

Advantages claimed for avoidance of the drain have been decreased OR times, lack of pain at removal and shorter hospital stay (4). Advantages of drain placement at laparoscopic prostatectomy have been early recognition of inadequate hemostasis and urine leak while allowing efflux of blood, urine and lymphatic fluid from the pelvis. Drain placement may reduce hematoma formation, which has been shown to cause bladder neck contractures and permanent incontinence in a significant percentage of patients when they occur (5).

We believe that the simple drain is not only acceptable but also essential to allow early diagnosis of postoperative problems and to prevent more serious issues evolving. I would have to see good evidence of the benefits in omitting drains to consider changing this practice.

\section{REFERENCES}

1. Araki M, Manoharan M, Vyas S, Nieder AM, Soloway MS: A pelvic drain can often be avoided after radical retropubic prostatectomy--an update in 552 cases. Eur Urol. 2006; 50: 1241-7; discussion 1246-7.

2. Savoie M, Soloway MS, Kim SS, Manoharan M: A pelvic drain may be avoided after radical retropubic prostatectomy. J Urol. 2003; 170: 112-4.

3. Sharma S, Kim HL, Mohler JL: Routine pelvic drainage not required after open or robotic radical prostatectomy. Urology. 2007; 69: 330-3.

4. Licht MR, Klein EA: Early hospital discharge after radical retropubic prostatectomy: impact on cost and complication rate. Urology. 1994; 44: 700-4.

5. Hedican SP, Walsh PC: Postoperative bleeding following radical retropubic prostatectomy. J Urol. 1994; 152: 1181-3.

\section{Dr. Vipul Patel Associate Clinical Professor of Surgery Associate Clinical Professor of Bioinformatics Director of Robotic \& Minimally Invasive Urologic Surgery The Ohio State University Columbus, Ohio, USA E-mail:myurologist@aol.com}

\section{REPLY BY THE AUTHORS}

We appreciate the thoughtful critique by Dr. Patel and are pleased that our article has sparked continued debate on the subject of pelvic drain placement following minimally invasive prostatectomy. $\mathrm{He}$ raises several points of criticism to which we would like to respond.
First, Dr. Patel notes that surgeons are moving to the "non-drained model". We do not support such a model, nor do we promote a sense of pride or cavalier behavior. Instead, we are promoting a selective drainage strategy. Furthermore, we believe that our selective drainage strategy as outlined in our 
article contains much of the "good evidence" that Dr. Patel calls for to settle this question, since no patient had a complication related to absence of a drain, and cystograms were obtained in virtually all patients.

In the era of evidence-based medicine, the question, "What is the downside?" is misdirected. Instead of asking, "why not?" we should demand that there be a robust reason for each of our maneuvers. Having initially presented this data at regional and national meetings, we observed the tendency of surgeons who, deeply accustomed to their routine, looked at the data and then tossed it aside to rely on gut feelings. Instead, we need to look closely at each potential complication for which at the outset we believe a drain will raise a red flag.

Is a pelvic drain a reliable signal of serious hemorrhage requiring reoperation in the immediate postoperative period? Probably not. In our series, there were no cases of hemorrhage or hematoma. We have all seen patients brought back to the operating room for severe bleeding within the first 24 hours after prostatectomy in whom a clotted Jackson-Pratt drain adjacent to a large hematoma had zero output. Of course, if hemostasis is truly concerning and appropriate measures have been taken, a drain should be placed, as was done for 2 patients in our series. However, drain or no drain, patients with serious postoperative bleeding will display clinical signs including decreasing hemoglobin, hemodynamic instability, oliguria, or abdominal distension. In over 2,000 patients undergoing minimally invasive prostatectomy in our experience, we have yet to see a patient with bloody drain output as the sole indicator of evolving problems.

Does a pelvic drain signal impending lymphocele formation? Absolutely not. As Dr. Patel points out, most patients are discharged within 24 hours without drains. On average, lymphoceles present 2 - 4 weeks after surgery, long after the drain has been removed. Evacuation of lymphatic fluid and/or diagnosing impending lymphoceles should not generally be used as a justification for drain placement.

Potential urinary extravasation from the anastomosis is the main justification for drain placement. We believe that a selective strategy can correctly identify those patients at risk for urine leak. In the remaining patients, the drain is simply unnecessary, and a potential source of pain and anxiety for the patient. As regards patient perception of the drain, we agree that the endpoints of validated pain scores and directed questionnaires are lacking in our study.

Dr. Patel has correctly stated that a prospective study is required, in which cystograms are performed at a set interval from surgery. Our study, while retrospective, is the first in the literature to contain cystograms in virtually all patients (206/208, or $99 \%)$, most of which were done within the first week $(90 \%$ of patients). However, we respectfully disagree with Dr. Patel's response in calling for randomization. Herein lies the key point: we do not advocate omitting drains in all patients, and randomizing patients to be drained or undrained would likely increase the incidence of undiagnosed complications. In fact, we advocate selection bias, in particular the bias of the senior surgeon. This is an active, selective strategy whereby drains are placed at the surgeon's discretion when concerns exist regarding the bladder neck, the anastomosis, or overall case complexity.

Our study adds to a growing body of literature that selective drain placement is likely to be required in $25 \%$ of cases (1-3). Can an experienced surgeon correctly identify the appropriate 1 out of 4 patients in whom drainage is required? Our data indicates the answer is definitely yes. Table 4 in our manuscript displays the true cystographic leak rate in the drained group is $15.6 \%$, compared to $2.5 \%$ in patients where a drain was deemed unnecessary $(\mathrm{p}=0.002)$. In the latter group, these were clinically insignificant extravasations, and no urinomas developed. This is reassuring evidence in support of a selective strategy for drain placement.

Having combined evidence from our own data and the other referenced studies, we have changed our practice. In the last 4 years, a selective drain placement strategy has not resulted in any measurable increase in morbidity. Readers need to decide individually how comfortable they are with this strategy and should not adopt this approach during the learning curve.

$$
\text { Respectfully, }
$$




\section{REFERENCES}

1. Savoie M, Soloway MS, Kim SS, Manoharan M: A pelvic drain may be avoided after radical retropubic prostatectomy. J Urol. 2003; 170:112-4

2. Araki M, Manoharan M, Vyas S, Nieder AM, Soloway MS: A pelvic drain can often be avoided after radical
Retropubic prostatectomy- an update in 552 cases. Eur urol. 2006; 50: 1241-7

3. Sharma S, Kim HL, Mohler JL: Routine pelvic drainage not required after open or robotic radical prostatectomy. Urology 2007; 69: 330-3.

\title{
Re: Gynecologic-Tract Sparing Extra Peritoneal Retrograde Radical Cystectomy with Neobladder
}

\author{
Jagdeesh N. Kulkarni, S. Jamal Rizvi, U. Purushotthama Acharya, K. S. Shiva Kumar, \\ P. Tiwari
}

\section{Department of Urology, Bombay Hospital Institute of Medical Sciences, Mumbai, India}

Int Braz J Urol, 34: 180-190, 2008

To the Editor,

Bladder cancer is considered the most prevalent malignant tumor affecting male in Egypt. Orthotopic ileal neobladder is currently the preferred continent urinary diversion in suitable patients undergoing radical cystectomy for muscle-invasive bladder cancer and may be considered the gold standard with which other forms of diversion are compared. Incorporation of antireflux system in orthotopic ileal neobladder substitutes is important in protecting the upper urinary tract in all patients undergoing continent diversion with a reasonable life expectancy. If this were not important, why is it that normal human bladder anatomy has evolved with an effective antireflux mechanism? Indeed, many antireflux techniques have been developed but the multiplicity of these techniques suggests that an ideal solution has not been found. All antireflux anastmosis have an inherent risk of functional failure (1).

Patients with carcinoma in situ of the prostatic urethra, tumors near bladder neck or infiltrating the prostate, multifocal papillary tumors, history of upper tract tumors or positive margins on frozen section of the transected proximal urethra must be excluded. For these patients, continent cutaneous diversion using the same technique will be evolved soon. After radical cystectomy in females, both ureters are intussuscepted in modified Sigma pouch but most of the females now prefer orthotopic ileal neobladder (2).

The new technique, which prevents reflux, has several advantages compared with antireflux techniques: technical simplicity and the procedure is suitable for all types of ureters including normal, dilated, short and irradiated ureters. It allows a non obstructed unidirectional flow of urine with minimal rate of stenosis and/or surgical revision so; it can protect the upper urinary tract. The use of foreign material like staples or meshes is avoided and the antireflux system is constructed from a minimal length of bowel segment decreasing metabolic complications associated with malabsorption or resorption. The afferent short limb provides extra length to reach the ureter, a tension free anastomosis, no risks of ureteral angulation with neobladder filling, and the possibility to resect the ureter far above the bladder, thus avoiding ureteral ischemia and distal recur- 